\title{
Breast Adenocarcinoma with Squamous Metaplasia
}

National Cancer Institute

\section{Source}

National Cancer Institute. Breast Adenocarcinoma with Squamous Metaplasia. NCI

Thesaurus. Code C5163.

An invasive breast carcinoma characterized by the presence of a predominant squamous cell component that is admixed with the adenocarcinoma component. 